\title{
Genetic variability in Italian populations of Drosophila suzukii
}

\author{
Gabriella Tait ${ }^{1,2^{*}}$ (D), Silvia Vezzulli', Fabiana Sassừ ${ }^{3}$, Gloria Antonini ${ }^{4}$, Antonio Biondi, Nuray Baser ${ }^{6}$, Giorgia Sollai ${ }^{7}$, \\ Alessandro Cini ${ }^{8}$, Lorenzo Tonina ${ }^{9}$, Lino Ometto ${ }^{1,11}$ and Gianfranco Anfora ${ }^{1,10}$
}

\begin{abstract}
Background: Drosophila suzukii is a highly destructive pest species, causing substantial economic losses in soft fruit production. To better understand migration patterns, gene flow and adaptation in invaded regions, we studied the genetic structure of D. suzukii collected across Italy, where it was first observed in 2008. In particular, we analysed 15 previously characterised Simple Sequence Repeat (SSR) markers to estimate genetic differentiation across the genome of 278 flies collected from nine populations.

Results: The nine populations showed high allelic diversity, mainly due to very high heterozygosity. The high Polymorphism Information Content (PIC) index values (ranging from 0.68 to 0.84 ) indicated good discrimination power for the markers. Negative fixation index $\left(F_{I S}\right)$ values in seven of the populations indicated a low level of inbreeding, as suggested by the high number of alleles. STRUCTURE, Principal Coordinate and Neighbour Joining analysis also revealed that the Sicilian population was fairly divergent compared to other Italian populations. Moreover, migration was present across all populations, with the exception of the Sicilian one, confirming its isolation relative to the mainland.
\end{abstract}

Conclusions: This is the first study characterising the genetic structure of the invasive species D. suzukii in Italy. Our analysis showed extensive genetic homogeneity among D. suzukii collected in Italy. The relatively isolated Sicilian population suggests a largely human-mediated migration pattern, while the warm climate in this region allows the production of soft fruit, and the associated D. suzukii reproductive season occurring much earlier than on the rest of the peninsula.

Keywords: Spotted wing drosophila, SSR markers, Population structure, Gene flow, Bottleneck, Human trade

\section{Background}

The spotted wing drosophila (SWD), Drosophila suzukii Matsumura (Diptera: Drosophilidae), is a pest species which has spread from its original range in Asia to a number of western countries in the past decade, including the Mediterranean basin [1], Europe, and USA [1-3]. The history of the geographical spread and infestation of $D$. suzukii is still under investigation: it is known that in 1939 this species was first recorded in Japan (Kanzawa 1939), while in the 1980s it was collected on the island of Hawaii [4]. Europe and the Americas were colonised much later,

\footnotetext{
* Correspondence: gabriella.tait@fmach.it

${ }^{1}$ Research and Innovation Centre, Fondazione Edmund Mach, San Michele all'Adige, Trento, Italy

${ }^{2}$ Department of Agricultural and Environmental Sciences, Udine Univeristy, Udine, Italy

Full list of author information is available at the end of the article
}

possibly during the last 9 years $[2,3,5,6]$. First adults of D. suzukii were caught contemporaneously in the region of Catalonia, Spain [7] and in Tuscany, Central Italy, in 2008 [3]. In 2009 D. suzukii individuals were found on both wild hosts (Vaccinium, Fragaria and Rubus spp.) and several species of cultivated berries in Trento Province, North Eastern Italy, where also the first economically important damage by this species in Europe was reported [8]. During the following years, D. suzukii has been spreading rapidly across Europe, with documented infestations ranging from Mediterranean regions (i.e. Greece, Turkey) to northern latitudes (i.e. Sweden, Poland, UK) (EPPO Global Database, Drosophila suzukii - DROSSU, 2017). In Italy, after the first detection, infestations were reported from the regions of Bolzano, Piedmont, Liguria, Campania and Veneto in 2010, from Lombardy, Emilia Romagna, Marche, Aosta Valley, Marche, Calabria and 
Sicily in 2011 [3], Sardinia in 2012 [9], Apulia in 2013 [10], Umbria in 2014 [11], and Latium in 2015 (Antonini G., present paper). Invasion dynamics can be studied using molecular markers that can discriminate and characterise the genetic relationships between source and derived populations, migration flows and population expansion patterns [12-14]. In particular, Single Nucleotide Polymorphism (SNP) and Simple Sequence Repeat (SSR) markers have played an increasingly significant role in the study of genetic differentiation across species populations [15]. Thanks to their great discrimination power and high reproducibility and variability, SSRs represent one of the most robust and informative molecular markers available for genotyping individuals [16]. For instance, their use in Drosophila species was pivotal in studying intrapopulation genetic variation and evolution [14, 17-20].

In relation to $D$. suzukii, SSRs have been exploited to study genetic aspects of the colonisation process in the USA and Europe. Jeffrey and colleagues based their research on the use of six X-linked genes and suggested that the invasions of the USA and Europe are two independent events [21]. Bahder et al. in particular analysed samples of D. suzukii populations collected in California and Washington and determined that while $D$. suzukii in the former region had high levels of genetic variation, the latter was highly monomorphic [22]. Furthermore, Fraimout's group investigated Hawaiian and Spanish populations by exploiting microsatellite markers, finding a significant level of genetic differentiation [23]. Although both studies exploited two different sets of microsatellites and tested different populations, the authors were led to similar conclusions: they demonstrated the presence of a specific differentiation process among ancestral and derived populations and suggested that for D. suzukii a genetic analysis approach is valuable not only to better understanding of the evolutionary history of the species, but also to manage its great potential for invasiveness. Different studies on the invasiveness of species, including $D$. suzukii, have demonstrated the relationship between their spread and human trade [24-26]. For this reason, it is very important to consider the correlation between gene flow analysis and the sale of soft fruit all over the country. Taking into account this aspect, we used a population genetic approach to characterise genetic diversity among $D$. suzukii individuals collected in different regions of Italy. In order to perform this work a set of 15 microsatellites validated by Fraimout and colleagues [23] were employed. The current research is the first study that provides new insights on the trend of genetic diversity in Italian populations of $D$. suzukii.

\section{Methods}

\section{Suzukii collection, identification and DNA extraction}

A total of 278 individuals of $D$. suzukii collected from nine populations in Italy were analysed (Fig. 1). Adult $D$. suzukii were collected between October 2015 and April 2016 using Droskidrink ${ }^{\circ}$-baited traps [27] left exposed for 3 days. In order to limit the likelihood of sampling individuals related to each other, three traps per location were used, at a distance of at least $500 \mathrm{~m}$ from each other. In the laboratory, D. suzukii individuals were identified using a $7 \times-45 \times$ stereomicroscope, according to Hauser's (2011) morphological characteristics, such as the structure of the ovipositor for females and spots on the wings and tarsal combs for males. Samples were preserved in $96 \%$ ethanol and kept at $4{ }^{\circ} \mathrm{C}$ until DNA extraction. For each location, we selected 15 females and 15 males for DNA extraction, with genomic DNA being extracted from each individual separately using the Macherey Nagel Kit (NucleoSpin Tissue, Macherey Nagel, Düren, Germany).

\section{Microsatellite analysis}

The SSRs used for this work were selected from a set of microsatellites previously designed and validated [23]. Of the 28 published SSRs, 22 continuous di-nucleotide loci were tested on a pool of $20 \mathrm{D}$. suzukii individuals. Seven of these loci were discarded because of amplification problems, leaving 15 SSR markers distributed across chromosomes 2 and 3 (Fig. 2) [28].

Each pair of primers was used for PCR amplification in $25 \mu \mathrm{L}$ final volume, containing $1 \mathrm{X}$ GoTaq G2 Master Mix, $0.5 \mu \mathrm{L}$ of each primer, $10.5 \mu \mathrm{L}$ of distilled deionized water and $1 \mu \mathrm{L}$ of genomic DNA. The PCR program was set with an initial period of denaturation at $94{ }^{\circ} \mathrm{C}(30 \mathrm{~s})$ followed by 32 cycles of additional denaturation at $94{ }^{\circ} \mathrm{C}$ (30 s), an annealing phase at $57{ }^{\circ} \mathrm{C}(1 \mathrm{~min} 30 \mathrm{~s})$, an elongation phase at $72{ }^{\circ} \mathrm{C}(1 \mathrm{~min})$, and ending with another extension phase at $72{ }^{\circ} \mathrm{C}(30 \mathrm{~min})$. PCR products were checked using electrophoresis on $1.5 \%$ agarose gel, stained with ethidium bromide and visualised under UV light. Each amplicon was then diluted 1:10 in distilled water and $1 \mu \mathrm{L}$ of this dilution was added to $12.5 \mu \mathrm{L}$ of a mixture of deionised Formamide (Sigma-Aldrich) and GeneScan-500 ROX size standard (Life Tech, Waltham, MA USA). Prior to denaturation for $4 \mathrm{~min}$ at $94{ }^{\circ} \mathrm{C}$, capillary electrophoresis was carried out in an ABI PRISM 310 Genetic Analyzer (Life Tech) and the fragments were sized with GeneMapper v.4.0 software in binning mode. If no sample amplification was obtained after two PCR attempts, the locus was classified as missing data.

\section{Statistical analysis}

Microsatellite allele data were processed with Tandem program v.1.08 [29]. GenAIEx software v.6.41 [30] was run to study the genetic variability between populations using the following statistics: mean number of alleles $\left(N_{\mathrm{a}}\right)$, effective number of alleles $\left(N_{\mathrm{e}}\right)$, expected heterozygosity $\left(H_{\mathrm{E}}\right)$, observed heterozygosity $\left(H_{\mathrm{O}}\right)$, number of 


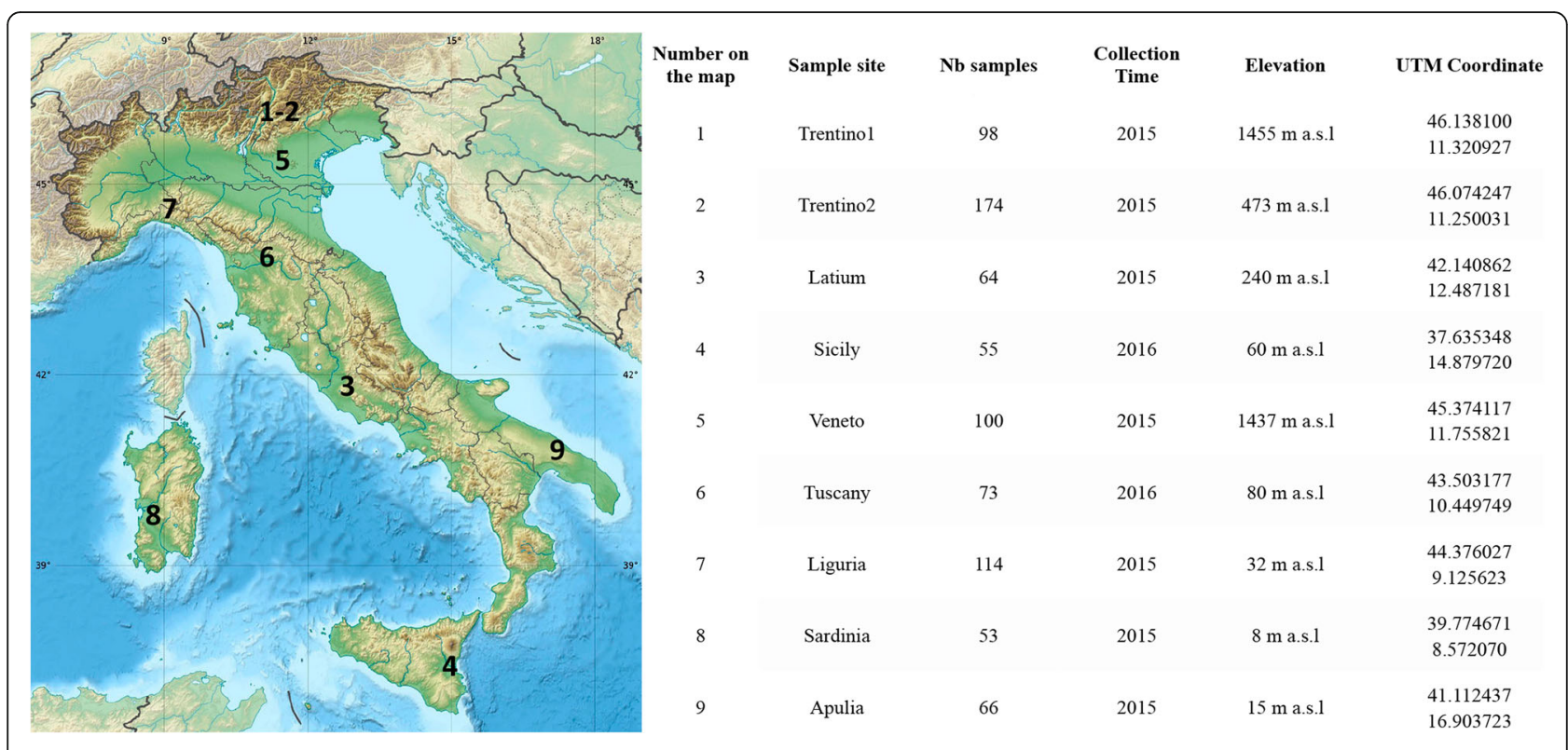

Fig. 1 Field collected samples of the D. suzukii analysed in this study. This image has been adapted from the original (https://it.wikipedia.org/wiki/ File:Italy_topographic_map-blank.svg) whose author is Eric Gaba, and it is licensed through Creative Commons Attribution 3.0

\section{Drosophila_2 Drosophila_3}
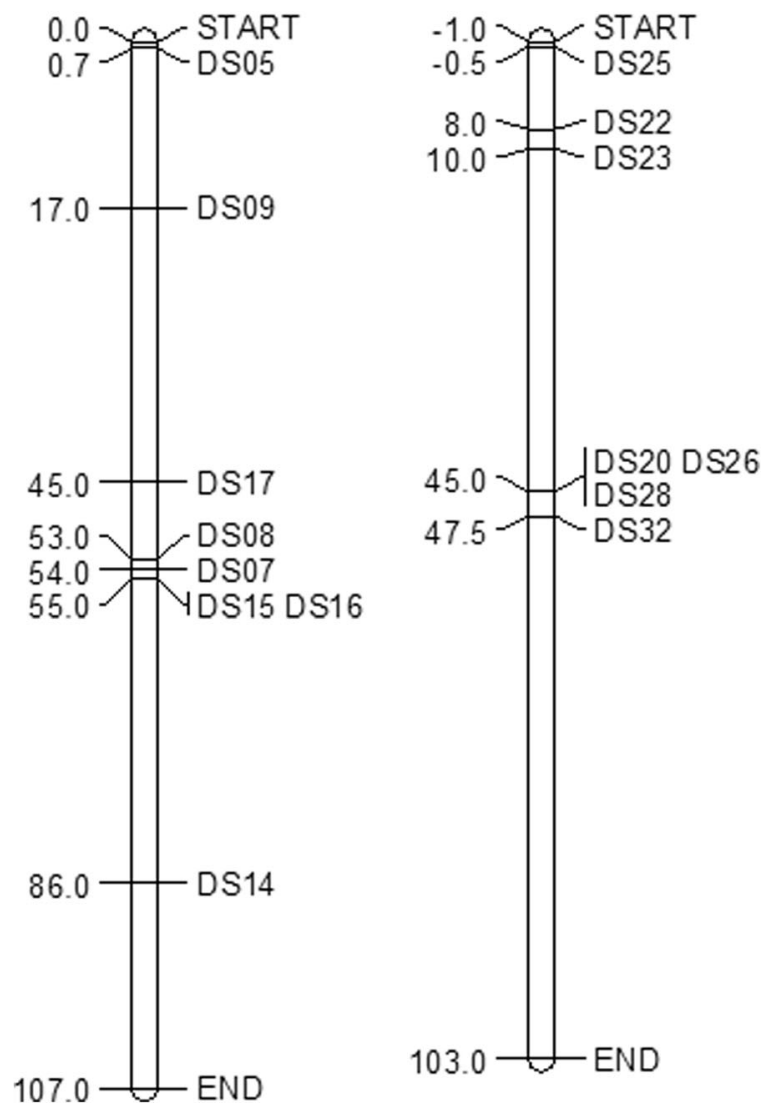

Fig. 2 Location of the 15 microsatellite markers distributed across the chromosomes 2 and 3 private alleles $\left(N_{\mathrm{p}}\right)$, frequency of private alleles $\left(A_{\mathrm{p}}\right)$ and inbreeding coefficient $\left(F_{\mathrm{IS}}\right)$. Allelic richness was calculated using FSTAT v.2.9.3 software [31]. Deviation from Hardy-Weinberg equilibrium after the Bonferroni multiple correction test and allelic Polymorphic Information Content (PIC) were tested using CERVUS software v.3.0 [32]. $N_{\mathrm{e}}$ and $H_{\mathrm{E}}$ were chosen as the basic genetic variability and estimated for each population. $N_{\mathrm{e}}$ was analysed with ANOVA using origin as a factor. $N_{\mathrm{e}}$ was taken from the formula $1 /\left(1-H_{\mathrm{E}}\right)$ and then tested with the non-parametric Tukey test [33]. $N_{\mathrm{e}}$ was used instead of $\left(N_{\mathrm{a}}\right)$, considering that it is less sensitive to rare alleles and sample size. $H_{\mathrm{E}}$ was taken from the formula $H_{\mathrm{E}}=1$ $\left(\Sigma q_{\mathrm{i}}^{2}\right)$, where $q_{\mathrm{i}}$ represents the frequency of the $i^{\text {th }}$ allele in the population. $H_{\mathrm{E}}$ was converted into $1 / H_{\mathrm{E}}$ and then tested with the non-parametric Kruskal Wallis test. All statistical analyses were performed using $\mathrm{R}$ software v.3.3.2. The significance level was set below 0.001 $(P<0.001)$ to minimise sources of uncertainty.

To evaluate the genetic structure of populations, we relied on multiple approaches: Principal Coordinate Analysis (PCoA), Neighbour Joining Tree, AMOVA analysis, measurement of the index of differentiation $\left(F_{\mathrm{ST}}\right)$ and use of a non-spatial Bayesian algorithm. These approaches were chosen in order to obtain a broad view of the genetic structure of this invasive species in Italy. PCoA, obtained with GenAIEx software, was used to display genetic divergence across $D$. suzukii in a multidimensional space, considering frequency data. Unrooted Neighbour Joining Tree based on Nei's genetic distance constructed using DARwin software was complementary to PCoA analysis [34]. AMOVA analysis obtained using 
the Arlequin v.3.5 [35] program was performed to estimate variability distribution within and between the tested groups. The level of genetic differentiation in populations was detected using the $F_{\mathrm{ST}}$ values obtained with Microsatellite Analyzer (MSA) v.4.05 software [19]. The program allows comparison of each observed $F_{\mathrm{ST}}$ value with that obtained in 10,000 matrix permutations in order to define the statistical significance of each $F_{\mathrm{ST}}$.

The Bayesian method was implemented with STRUCTURE software v.2.3.3 [36, 37]. This program was employed in order to obtain clusters of individual genotypes. The analysis was run using the admixture hypothesis, which is based on correlated allele frequencies, in which each sample contains a portion of the genome of each ancestral population. This, correlated to the allele frequency model, allows calculation of the log likelihood for the data, $\mathrm{L}(\mathrm{K})$. Not knowing the origin and the degree of isolation of the studied populations a priori, this model is considered to be the most appropriate in these situations [36]. Prior probability, i.e. the probability that an individual belongs to any $\mathrm{K}$ reference populations, is defined as $1 / K$. The $\mathrm{K}$ value was fixed from 1 to 10 with 20 replicates of each $K$ to test the convergence of the Markov chain. A total of 1000,000 simulations per run and 500,000 Markov Chain Monte Carlo MCMC repetitions were fixed. Once the results were obtained, they were scored with STRUCTURE HARVESTER software to detect the number of $\mathrm{K}$ groups that best fit the dataset according to the Evanno test [38, 39]. GENECLASS v.2.0 [40] was run to estimate the probability of each individual in a population belonging only to that population, the probability of it being an immigrant from each of the other populations, and the probability of it being a migrant to the other populations. BOTTLENECK v.1.2.02 [41] was run in order to evaluate whether demographic events such as population contraction or expansion took place in each population.

Heterozygosity excess, which is associated with a population expansion, was tested with the two-phase mutation model (TPM) using Wilcoxon signed-rank test, which according to Piry et al. is the most appropriate and powerful test when dealing with less than twenty loci [41]. Parameters were set as $20 \%$ multiple-step mutations and $80 \%$ single-step mutations with 1000 iterations. In order to verify the effect of isolation by distance, and therefore to find possible correlation between genetic and geographical distances, the ISOLDE option in GENEPOP software was run.

\section{Results}

\section{Genetic diversity}

The variability indices of the 15 SSR loci are shown in Table 1 . The number of alleles per locus across populations ranged from 8 (DS17) to 20 (DS07), with an
Table 1 Summary of the genetic variability at 15 microsatellite loci

\begin{tabular}{llllllll}
\hline Locus & Repeat & PIC & Allele range & $N$ & $H_{O}$ & $H_{E}$ & $H-W$ \\
\hline DS05 & (TG)10 & 0.74 & $250-284 \mathrm{bp}$ & 11 & 0.79 & 0.77 & $* *$ \\
DS07 & (CA)13 & 0.84 & $180-220 \mathrm{bp}$ & 20 & 0.89 & 0.86 & NS \\
DS08 & (AG)10 & 0.81 & $118-158 \mathrm{bp}$ & 17 & 0.84 & 0.83 & $* * *$ \\
DS09 & (AC)15 & 0.72 & $200-230 \mathrm{bp}$ & 13 & 0.71 & 0.75 & $\mathrm{NS}$ \\
DS14 & (TG)10 & 0.68 & $136-239 \mathrm{bp}$ & 11 & 0.75 & 0.71 & $* *$ \\
DS15 & (GT)11 & 0.76 & $238-278 \mathrm{bp}$ & 13 & 0.88 & 0.79 & $*$ \\
DS16 & (AC)13 & 0.78 & $85-119 \mathrm{bp}$ & 15 & 0.91 & 0.81 & $* * *$ \\
DS17 & (GT)10 & 0.70 & $93-113 \mathrm{bp}$ & 8 & 0.90 & 0.74 & $* * *$ \\
DS20 & (AG)12 & 0.74 & $207-235 \mathrm{bp}$ & 13 & 0.84 & 0.77 & $*$ \\
DS22 & (GT)11 & 0.71 & $304-334 \mathrm{bp}$ & 13 & 0.83 & 0.75 & NS \\
DS23 & (AC)10 & 0.75 & $236-266 \mathrm{bp}$ & 13 & 0.76 & 0.77 & NS \\
DS25 & (CA)10 & 0.71 & $222-280 \mathrm{bp}$ & 18 & 0.74 & 0.74 & $* * *$ \\
DS26 & (CA)10 & 0.73 & $79-109 \mathrm{bp}$ & 10 & 0.76 & 0.77 & NS \\
DS28 & (TG)11 & 0.78 & $141-161 \mathrm{bp}$ & 11 & 0.86 & 0.81 & $* * *$ \\
DS32 & (TG)15 & 0.83 & $310-376 \mathrm{bp}$ & 18 & 0.68 & 0.85 & $* * *$ \\
\hline
\end{tabular}

Repeat, motive of the microsatellite; PIC polymorphic information content; Allele range, $N$ number of alleles, $\mathrm{Ho}$,observed heterozygosity, $\mathrm{He}$ expected heterozygosity

average ( \pm standard deviation) of $13.6 \pm 3.37$. The PIC estimate ranged from 0.68 (DS14) to 0.84 (DS07), suggesting that this set of loci is informative for population analysis. Only five alleles were in Hardy-Weinberg Equilibrium (DS07, DS09, DS22, DS23, DS26), while the other 10 showed significant HWE deviations, with nine loci having an excess of $H_{\mathrm{O}}$ (Table 1). The reason for the HWE disequilibrium could be the presence of null allele that may affect estimation of population differentiation [42, 43]. The mean $H_{\mathrm{O}}$ across loci ranged from 0.68 (DS32) to 0.91 (DS16), while $H_{\mathrm{E}}$ ranged from 0.71 (DS14) to 0.86 (DS07). Mean $H_{\mathrm{O}}$ across populations ranged from $0.66 \pm 0.16$ (Trentino2), to $0.89 \pm 0.09$ (Tuscany) (Table 2). Allelic richness ranged from 6.23 in Trentino1 to 8.58 in Apulia. For most of the loci the $F_{\mathrm{IS}}$ was negative. $F_{\text {IS }}$ values ranged from -0.28 in Sicily to 0.07 in Trentino2. In the Additional file 1 are reported all the data concerning the observed and expected heterozygosity, the number of alleles, the effective number of alleles, the number of private alleles, the F-statistic ( $F$ is, Fit and Fst) and the fixation index. The Tukey test revealed a significant effect of population origin on the heterogeneity of $N_{\mathrm{e}}$ on comparing the following sampled populations: Trentino1 and Apulia, Trentino 2 and Apulia, Sicily and Apulia, and Sicily and Tuscany $(P<0.001)$. On analysing all the populations together with ANOVA, using the collection site as a factor, $N_{\mathrm{e}}$ showed a significant difference between populations $\left(F=3.86, P<10^{-10}\right)$. The effect of the collection site was also evident in mean $H_{\mathrm{E}}(\mathrm{F} 4.19, \mathrm{P}<0.001)$. 
Table $\mathbf{2}$ Level of genetic diversity across 9 populations of D. suzukii

\begin{tabular}{llllllllll}
\hline & $N_{a}$ & $N_{e}$ & $A_{r}$ & $N_{p}$ & $A_{p}$ & $H_{0}$ & $H_{E}$ & $A_{n}$ \\
\hline Trentino1 & $6.40 \pm 1.29$ & $3.65 \pm 0.93$ & 6.23 & 1 & 0.06 & $0.68 \pm 0.18$ & $0.70 \pm 0.07$ & 0.01 & 0.02 \\
Trentino2 & $7.60 \pm 1.50$ & $3.83 \pm 1.01$ & 7.36 & 8 & 0.53 & $0.66 \pm 0.16$ & $0.72 \pm 0.08$ & 0.03 & 0.07 \\
Sardinia & $7.87 \pm 1.40$ & $4.37 \pm 0.80$ & 7.69 & 6 & 0.40 & $0.82 \pm 0.10$ & $0.76 \pm 0.05$ & 0.03 & -0.08 \\
Latium & $7.80 \pm 1.37$ & $4.18 \pm 0.87$ & 7.44 & 6 & 0.40 & $0.83 \pm 0.13$ & $0.74 \pm 0.06$ & 0.04 & -0.11 \\
Sicily & $5.60 \pm 0.98$ & $3.25 \pm 0.58$ & 5.44 & 1 & 0.06 & $0.87 \pm 0.11$ & $0.68 \pm 0.05$ & 0.11 & -0.28 \\
Apulia & $8.87 \pm 3.44$ & $5.22 \pm 2.53$ & 8.58 & 25 & 1.66 & $0.81 \pm 0.13$ & $0.77 \pm 0.07$ & 0.01 & -0.04 \\
Tuscany & $7.47 \pm 1.12$ & $4.68 \pm 0.98$ & 7.23 & 2 & 0.13 & $0.89 \pm 0.09$ & $0.77 \pm 0.04$ & 0.06 & -0.14 \\
Liguria & $7.40 \pm 1.50$ & $4.41 \pm 0.77$ & 7.11 & 3 & 0.20 & $0.87 \pm 0.10$ & $0.76 \pm 0.03$ & 0.05 & -0.13 \\
Veneto & $7.53 \pm 1.30$ & $4.14 \pm 0.50$ & 7.26 & 5 & 0.33 & $0.83 \pm 0.16$ & $0.75 \pm 0.02$ & 0.04 & -0.10 \\
\hline
\end{tabular}

$N_{\mathrm{a}}$ mean number of alleles, $N_{\mathrm{e}}$ mean effective number of alleles, $A_{\mathrm{r}}$ mean of allele richness, $N_{\mathrm{p}}$ number of private alleles, $A_{\mathrm{p}}$ mean frequency of private alleles, $H_{\mathrm{O}}$ mean observed heterozygosity, $H_{\mathrm{E}}$ mean expected heterozygosity, $A_{\mathrm{n}}$ mean frequency of null alleles, $F_{\mathrm{IS}}$ mean inbreeding coefficient

\section{Genetic population structure and gene flow}

An estimate of variability distribution (AMOVA) within the tested populations indicated that $96 \%$ of the variation occurred within individuals, while only $4 \%$ of total variation was detected between populations. Table 3 gives a summary of analysis of variance for the nine $D$. suzukii populations. The results of PCoA are shown in Fig. 3. The first axis explains $57.9 \%$ of genetic variation, while the second axis explains $18.9 \%$. The first axis separates the Sicilian population from the remaining populations. The second axis mainly divides Apulia, Tuscany, Liguria and Veneto from the others. The unweighted Neighbour-Joining dendrogram represented in Fig. 4 supports data obtained using PCoA: the Sicilian group has the same origin as the other populations, but individuals belong to a separated cluster.

The $F_{\mathrm{ST}}$ values confirmed the genetic differentiation between the Sicilian group and the others. Considering all the populations, 30 of the 36 pairwise comparisons tested were significantly different from zero (Table 4). The least significant differentiation was between Liguria and Veneto $\left(F_{\mathrm{ST}}=0.003\right)$, while the greatest divergence was between Sicily and Trentino1 $\left(F_{\mathrm{ST}}=0.135\right)$. Population structure analysis led to the identification of two clusters $(K=2)$, based on the Evanno method (Fig. 5) and revealed genetic homogeneity between most populations, with the exception of flies collected in Sicily. The data of gene flow are reported in Table 5. The findings show that the Sicilian population did not migrate significantly to any other populations $(\mathrm{m}<0.100)$. Although there was no gene flow from Sicily to the other regions, migrant flow occurred from Trentino2 $(\mathrm{m}=0.100)$,

Table 3 Analysis of molecular variance test (AMOVA)

\begin{tabular}{lllll}
\hline Source of variation & DF & SS & VC & $\% P V$ \\
\hline Among Populations & 8 & 165.16 & 0.24 & $4 \%$ \\
Within Individuals & 278 & 167.05 & 6.00 & $96 \%$ \\
\hline
\end{tabular}

$D F$ degree of freedom, SS sum of squares, VC variance components, \%PV percentage of total variation
Sardinia $(\mathrm{m}=0.176)$, Lazio $(\mathrm{m}=0.281)$, Tuscany $(\mathrm{m}=0.195)$, and Liguria $(\mathrm{m}=0.111)$. On the other hand, migration occurred from Apulia to other regions, but not to Apulia $(m<0.100)$ from other regions. Excluding Sicily and Apulia, the remaining seven populations both received and provided significant genetic information in relation to other populations $(\mathrm{m}>100)$. Comparisons of Trentino 2 and Veneto $(\mathrm{m}=0.430$ and $\mathrm{m}=0.485$ respectively), Sardinia and Tuscany $(\mathrm{m}=0.316$ and $\mathrm{m}=0.327$ respectively) and Lazio and Liguria ( $\mathrm{m}=0.376$ and $\mathrm{m}=0.315$ respectively) revealed a similar migration rate in both directions. Considering the likelihood of the presence of migrants across populations, nine migrants (seven females and two males) were detected with a probability of less than 0.01 .

Results from the individual population analysis using the TPM model did not support an expansion scenario. On the contrary, population bottleneck, defined by significant heterozygote deficiency was present in the Trentino2 population $(P=0.004)$. The nine populations showed no significant correlation when comparing genetic and geographical distances $\left[R^{2}=0.014, P=0.568, F_{\mathrm{ST}} /(1-\right.$ $\left.F_{\mathrm{ST}}\right)=0.049+\operatorname{Ln}($ geographical distance $\left.)=0.001\right]$.

\section{Discussion}

\section{Genetic diversity}

The introduction of invasive species to new environments poses threats to biodiversity, agriculture, public health and ecosystem integrity [44-47]. For this reason, considerable attention is paid to the rapid spread of alien species $[46,48]$. Genetic characteristics deeply affect the capacity for expansion [49]. Therefore, in order to mitigate their impact and define management strategies it is imperative to study these fundamental characteristics. Currently techniques such as genomics [50-52], transcriptomics $[53,54]$, and metagenomics $[55,56]$ allow us to investigate these basic traits.

This research investigated the genetic structure of $D$. suzukii collected in different areas of Italy. In particular, 


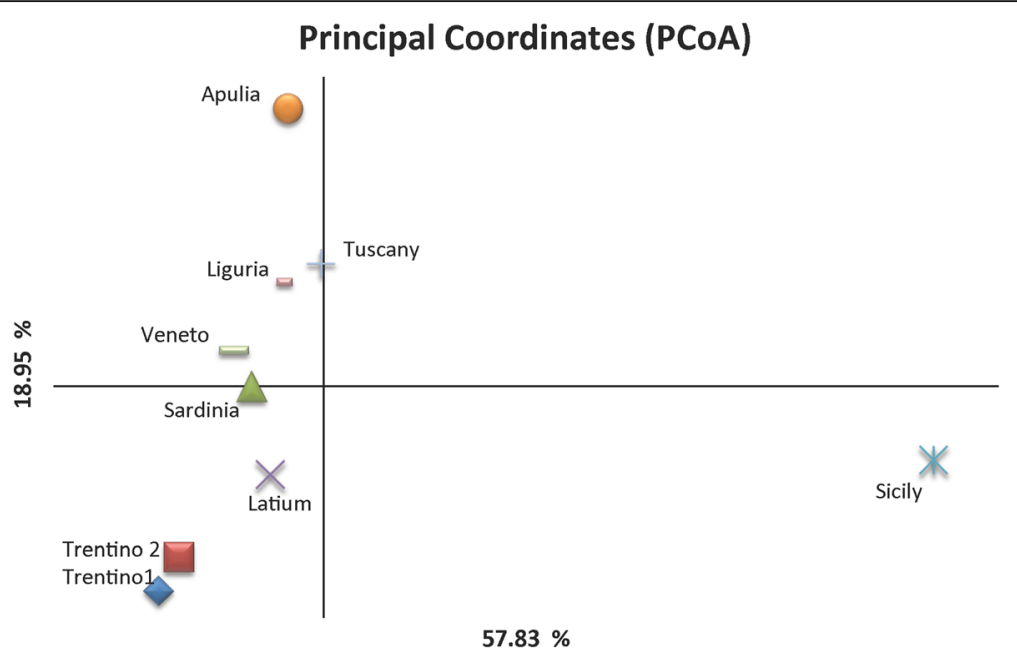

Fig. 3 Principal coordinate analysis (PCOA) of nine populations generated from genetic distance calculation in GenAlEx program

the aim of the analyses was to understand the gene flow of this species in a newly colonised environment. Our findings help to better understand the dynamics and complexity of this invasive species in Italy. The nine populations studied show a high level of genetic variation. The high number of alleles per locus detected clearly demonstrated the discriminatory power of these markers. Taking into consideration $N_{\mathrm{e}}, H_{\mathrm{E}}$ and $H_{\mathrm{O}}$, it is evident that the level of genetic differentiation is similar in D. suzukii collected across Italy, even in the locations at the greatest distance from the likely spreading centre of the species in Italy [25]. The high level of heterozygosity could be explained by good adaptation to new ranges due to a favourable environment, their reproductive power, and the absence or limited presence of natural competitors and predators $[57,58]$. Bahder et al. found that populations from Washington were much less polymorphic than those in California, suggesting a recent strong population bottleneck associated to the recent invasion of the former [22]. Washington has a much cooler climate than California, similar to the contrast between Trentino and the rest of Italy. However, we did not observe such a contrast in heterozygosity, probably due to the highly favourable habitat found in Trentino coupled with a high migration rate with the rest of the Italian populations. Heterozygosity deficiency was

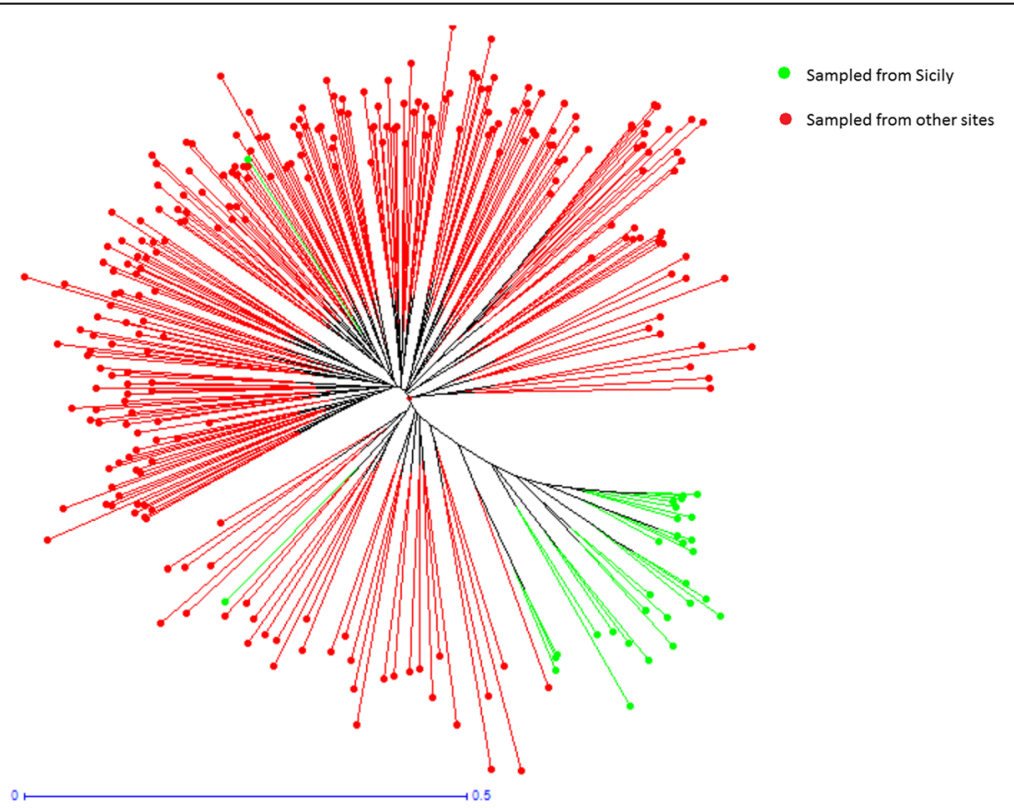

Fig. 4 Unrooted neighbour joining (UNJ) tree obtained from DARwin software. Each brunch represents single individual 
Table 4 Pairwise Fst among the nine populations of D. suzukii

\begin{tabular}{|c|c|c|c|c|c|c|c|c|c|}
\hline & Trentino1 & Trentino2 & Sardinia & Latium & Sicily & Apulia & Tuscany & Liguria & Veneto \\
\hline Trentino1 & 0.000 & & & & & & & & \\
\hline Trentino2 & 0.006 & 0.000 & & & & & & & \\
\hline Sardinia & 0.022 & 0.011 & 0.000 & & & & & & \\
\hline Latium & 0.009 & 0.007 & 0.017 & 0.000 & & & & & \\
\hline Sicily & 0.135 & 0.121 & 0.109 & 0.097 & 0.000 & & & & \\
\hline Apulia & 0.051 & 0.040 & 0.038 & 0.036 & 0.116 & 0.000 & & & \\
\hline Tuscany & 0.039 & 0.031 & 0.015 & 0.022 & 0.097 & 0.038 & 0.000 & & \\
\hline Liguria & 0.026 & 0.017 & 0.010 & 0.018 & 0.096 & 0.033 & 0.015 & 0.000 & \\
\hline Veneto & 0.022 & 0.006 & 0.008 & 0.012 & 0.113 & 0.036 & 0.017 & 0.003 & 0.000 \\
\hline
\end{tabular}

Boldface indicates values significantly different from zero $(P=0.05)$

detected for one out of the nine investigated populations. In contrast, the remaining eight groups showed heterozygosity excess. Sicily in particular had the lowest heterozygosity value $(-0.28)$. Negative results indicate random mating, therefore a lack of inbreeding among the collected individuals. In contrast, Trentino1 and Trentino 2 had a positive $F_{\text {IS }}$ value, indicating inbreeding. The Apulian population showed the greatest number of private alleles (25). This could be the consequence of a steady introduction of new alleles due to migration, possibly associated with human-mediated transport $[25,59]$.

\section{Genetic structure analysis}

Moderate genetic differentiation between most of the groups was in evidence for the nine populations, while the Sicilian population was the most differentiated from the others. This is supported by the NJ tree, PCoA data and structural analysis. At the same time, low differentiation between the other populations may be due to gene flow, which can homogenize gene frequency across populations. Data concerning the reduction or expansion of the studied populations indicated that Trentino 2 was the only group having indices of genetic bottleneck.

\section{Migration pattern}

Human transportation is the most probable explanation for the extensive spread of D. suzukii. [25, 59].
When an alien species is introduced into an environment outside its native range, expansion can be identified not only by analysing genetic diversity indices, but also by analysing the genetic flow between populations, which is a direct proof of rapid distribution. $[60,61]$. In particular, in the last 40 years, the risk of biotic invaders has increased significantly because of levels of international trade not seen before [62]. This situation facilitates genetic flow between groups located in different locations, and may well apply to the results of our study. For instance, the observation that the level of heterozygosity $\left(F_{\mathrm{st}}\right)$ does not clearly decline (increase) from the hypothetical source population (Livorno, Tuscany) and that there is a high migration rate among localities, suggests that $D$. suzukii moves extensively across most of the Italian peninsula. Most of the Sicilian production of vegetables and fruit, including high D. suzukii susceptible hosts, is frequently exported to central and northern Italy. While this could suggest a high probability of flies being transported between Sicily and the rest of the peninsula, our results indicate that there was no gene flow from Sicily to other regions. This is probably due to the fact that ripe fruits are exported from $\mathrm{Si}$ cily mostly during the cold season, when moderate temperatures allow the production of berry fruit in Sicily, but not in the rest of Italy. Therefore, any $D$. suzukii accidentally moving from Sicily to the rest of

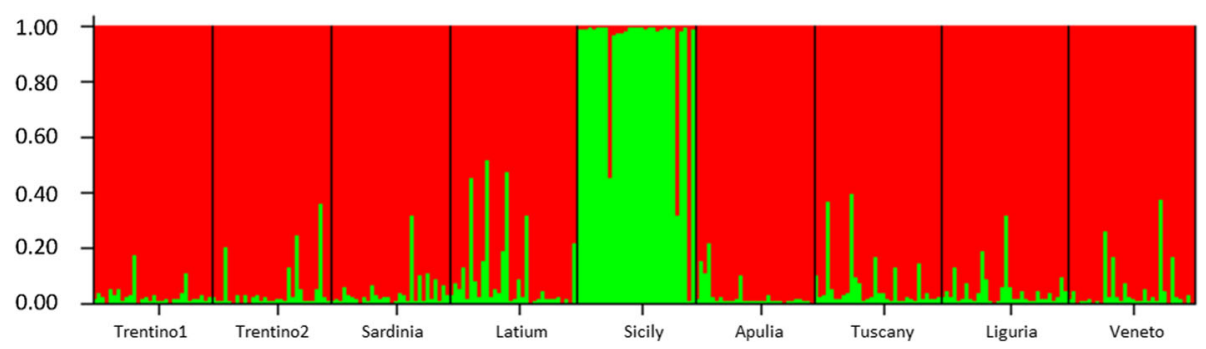

Fig. 5 Genetic structure of nine Italian D. suzukii populations estimated by structure analysis 
Table 5 Individual assignment analysis obtained using GENECLASS

\begin{tabular}{llllllllll}
\hline & Trentino1 & Trentino2 & Sardinia & Latium & Sicily & Apulia & Tuscany & Liguria & Veneto \\
\hline Trentino1 & $\mathbf{0 . 3 9 1}$ & $\mathbf{0 . 5 1 2}$ & $\mathbf{0 . 5 1 8}$ & $\mathbf{0 . 6 0 4}$ & 0.004 & $\mathbf{0 . 2 7 2}$ & $\mathbf{0 . 3 4 4}$ & $\mathbf{0 . 4 8 2}$ & $\mathbf{0 . 4 8 5}$ \\
Trentino2 & $\mathbf{0 . 2 8 8}$ & $\mathbf{0 . 4 7 7}$ & $\mathbf{0 . 4 9 2}$ & $\mathbf{0 . 5 2 4}$ & 0.008 & $\mathbf{0 . 3 0 7}$ & $\mathbf{0 . 3 9 4}$ & $\mathbf{0 . 5 0 6}$ & $\mathbf{0 . 4 8 5}$ \\
Sardinia & 0.087 & $\mathbf{0 . 2 5 4}$ & $\mathbf{0 . 4 4 4}$ & $\mathbf{0 . 2 7 0}$ & 0.005 & $\mathbf{0 . 1 3 8}$ & $\mathbf{0 . 3 2 7}$ & $\mathbf{0 . 3 0 5}$ & $\mathbf{0 . 3 0 1}$ \\
Latium & $\mathbf{0 . 1 4 9}$ & $\mathbf{0 . 3 8 6}$ & $\mathbf{0 . 3 4 9}$ & $\mathbf{0 . 4 7 2}$ & 0.008 & $\mathbf{0 . 1 9 4}$ & $\mathbf{0 . 3 2 4}$ & $\mathbf{0 . 3 1 5}$ & $\mathbf{0 . 2 7 0}$ \\
Sicily & 0.015 & $\mathbf{0 . 1 0 0}$ & $\mathbf{0 . 1 7 6}$ & $\mathbf{0 . 2 8 1}$ & $\mathbf{0 . 6 1 1}$ & 0.064 & $\mathbf{0 . 1 9 5}$ & $\mathbf{0 . 1 1 1}$ & 0.089 \\
Apulia & 0.008 & 0.084 & 0.051 & 0.056 & 0.001 & $\mathbf{0 . 3 7 7}$ & 0.049 & 0.040 & 0.053 \\
Tuscany & 0.052 & $\mathbf{0 . 1 6 2}$ & $\mathbf{0 . 3 1 6}$ & $\mathbf{0 . 2 0 9}$ & 0.006 & $\mathbf{0 . 1 1 5}$ & $\mathbf{0 . 5 6 7}$ & $\mathbf{0 . 2 6 6}$ & $\mathbf{0 . 1 7 6}$ \\
Liguria & $\mathbf{0 . 1 0 9}$ & $\mathbf{0 . 3 6 2}$ & $\mathbf{0 . 4 2 3}$ & $\mathbf{0 . 3 7 6}$ & 0.004 & $\mathbf{0 . 2 0 4}$ & $\mathbf{0 . 3 8 8}$ & $\mathbf{0 . 4 6 6}$ & $\mathbf{0 . 3 4 4}$ \\
Veneto & $\mathbf{0 . 1 8 3}$ & $\mathbf{0 . 4 3 0}$ & $\mathbf{0 . 4 5 4}$ & $\mathbf{0 . 4 5 6}$ & 0.006 & $\mathbf{0 . 2 8 3}$ & $\mathbf{0 . 4 0 1}$ & $\mathbf{0 . 4 7 3}$ & $\mathbf{0 . 5 6 4}$ \\
\hline
\end{tabular}

Boldface indicates significant migration rate values $(m \geq 100)$

Italy would arrive at a time when the local population is made up of a few individuals in winter diapause [27].

A second interesting piece of information revealed by our results is related to the scenario in Sardinia. To satisfy local demand for berry fruit, this region imports fruit from Italy and northern Europe, Spain, the USA and South America. The flies used in this study were collected in Arborea, a town $13 \mathrm{~km}$ away from the port of Oristano, one of the most important commercial ports in Italy. Thus, it is likely that the Sardinian population is made up of immigrants from other regions, as suggested by the low differentiation between this population and those on the mainland.

\section{Conclusion}

This research represents the first study investigating the pattern of genetic variability for $D$. suzukii following its introduction to Italy. Defining the population structure of a species, in particular of an invasive species, it is necessary not only to improve our knowledge of the genetic architecture, but also to apply knowledge. Indeed, understanding the current genetic structure of D. suzukii has significant implications in relation to geographical and economic impact. The evaluation of the genetic status of the D. suzukii populations in newly invaded areas and their expansion or reduction phases during defined periods of the year, may thus provide valuable information for predicting population spread, outbreaks, and improve integrated pest management programmes. Proper genetic management practices for D. suzukii and constant monitoring are therefore critical for maintaining populations under control.

The information obtained can be applied in particular to the management of coastal areas; one important action could be to increase monitoring control with the use of traps and other early warning tools in order to limit either multiple reintroductions of the same species or new introductions of exotic organisms.

\section{Additional file}

Additional file 1: Data explained allele frequencies for each locus at each location. Are in more reported the observed and expected heterozygosity, the number of alleles, the effective number of alleles, the number of private alleles, the F-statistic (Fis, Fit and Fst) and the fixation index. (XLSX $246 \mathrm{~kb})$

\section{Acknowledgements}

The authors are grateful to Prof. Giuseppe Firrao (University of Udine) for his availability and support, to Dr. Umberto Salvagnin for his assistance in figure preparation, and to Drs. Lara Giongo, Alberto Grassi and Elisabetta

Leonardelli for their helpful comments. We also thank Vivienne Frankell and Linda Brewer who helped with the English language revision.

Funding

Funding for this research was provided by Fondazione Edmund Mach.

Availability of data and materials

The data supporting the results of this article are included in the article and the supplementary information.

\section{Authors' contributions}

GT contributed to all the steps, planning the experimental design, sampling populations, conducting laboratory tests and data analysis, as well as writing the manuscript. SV participated in genetic data analysis and drafting the manuscript. SV and LO contributed to data interpretation. FS contributed to laboratory experiments. GfA and GIA contributed to sampling populations, suggesting professional contacts and conceiving the main idea. AB, NB, GS, $A C$ and LT contributed to sampling populations. All the authors have read and approved the final manuscript.

Ethics approval and consent to participate No specific permits were required for this project. Drosophila suzukii is an agricultural pest, not a protected species. All the insects analysed were collected in the open field and not from national parks or protected areas.

Consent for publication

Not applicable

Competing interests

The authors declare that they have no competing interest.

\section{Publisher's Note}

Springer Nature remains neutral with regard to jurisdictional claims in published maps and institutional affiliations. 


\section{Author details}

${ }^{1}$ Research and Innovation Centre, Fondazione Edmund Mach, San Michele all'Adige, Trento, Italy. ${ }^{2}$ Department of Agricultural and Environmental Sciences, Udine Univeristy, Udine, Italy. ${ }^{3}$ Division of Nuclear Techniques in Food and Agriculture, FAO/IAEA, Wien, Austria. " "Charles Darwin" Department of Biology and Biotechnologies, Sapienza University, Rome, Italy. ${ }^{5}$ Department of Agriculture, Food and Environment, Catania University, Catania, Italy. ${ }^{6}$ Mediterranean Agronomic Institut, Valenzano, Bari, Italy. ${ }^{7}$ Department of Biomedical Science, Cagliari University, Cagliari, Italy. ${ }^{8}$ Centre for Biodiversity and Environment Research, London College University, London, UK. ${ }^{9}$ Department of Agronomy, Padova University, Padova, Italy. ${ }^{10}$ Center of Agriculture Food Environment, Trento University, San Michele all'Adige, Trento, Italy. ${ }^{11}$ Current address: Independent Researcher, Mezzocorona, Trento, Italy.

Received: 12 April 2017 Accepted: 4 October 2017

Published online: 03 November 2017

\section{References}

1. Asplen MK, Anfora G, Biondi A, Choi DS, Chu D, Daane KM, Gibert P, Gutierrez AP, Hoelmer KA, Hutcison WD, Isaacs R, Jiang ZL, Kàrpàti Z, Kinura MT, Pascual M, Philips CR, Plantamp C, Ponti L, Vétek G, Vogt H, Walton VM, Yu Y, Zappalà L, Desneux N. Invasion biology of spotted wing drosophila (Drosophila suzukii): a global perspective and future priorities. J Pest Sci. 2015;88(3):469-94.

2. Hauser M. A historic account of the invasion of Drosophila suzukii (Matsumura) (Diptera: Drosophilidae) in the continental United States, with remarks on their identification. Pest Manag Sci. 2011;67(11):1352-7.

3. Cini A, loriatti C, Anfora G. A review of the invasion of Drosophila suzukii in Europe and a draft research agenda for integrated pest management. Bull Insectol. 2012;65(1):149-60.

4. Orhan A, Aslantaş R, Önder BŞ, Tozlu G. First record of the invasive vinegar fly Drosophila suzukii (Matsumura) (Diptera: Drosophilidae) from eastern Turkey. Turkish J Zool. 2016;40(2):290-3.

5. Lee JC, Bruck DJ, Dreves AJ, loriatti C, Vogt H, Baufeld P. In focus: spotted wing drosophila, Drosophila suzukii, across perspectives. Pest Manag Sci. 2011;67(11):1349-51.

6. Deprá M, Poppe JL, Schmitz HJ, De Toni DC, Valente VLS. The first records of the invasive pest Drosophila suzukii in the south American continent. J Pest Sci. 2014;87(3):379-83.

7. Calabria G, Máca J, Bächli G, Serra L, Pascual M. First records of the potential pest species Drosophila suzukii (Diptera: Drosophilidae) in Europe. J Appl Entomol. 2012;136(1-2):139-47.

8. Grassi A, Palmieri L, Giongo L. Nuovo fitofago per i piccoli frutti in Trentino. Terra Trentina. 2009;55(10):19-23. http://hdl.handle.net/10449/19083

9. Marongiu G, Marras PM, Ramassini W. First record of Drosophila suzukii in Sardinia (Italy). Protezione delle Colture. 2013;3:34.

10. Baser N, Ouantar M, Broutou O, Lamaj F, Verrastro V, Porcelli F. First finding of Drosophila suzukii (Matsumura) (Diptera : Drosophilidae) in Apulia, Italy, and its population dynamics throughout the year. Fruits. 2015;70(4):225-30.

11. Romani R, Natalini G. Prima segnalazione di Drosophila suzukii in Umbria. L'Informatore Agrario. 2015;71(7):64-5.

12. Sunnucks P, De Barro PJ, Lushai G, Maclean N, Hales D. Genetic structure of an aphid studied using microsatellites: cyclic parthenogenesis, differentiated lineages and host specialization. Mol Ecol. 1997;6:1059-73.

13. Jarne P, Lagoda PJL. Microsatellites, from molecules to populations and back. Trends Ecol Evol. 1996;11(10):424-9.

14. Schlötterer $C$. The evolution of molecular markers -just a matter of fashion? Nat Rev Genet. 2004;5(1):63-9.

15. Morin PA, Mccarthy M. Highly accurate SNP genotyping from historical and low-quality samples. Mol Ecol Notes. 2007;7(6):937-46.

16. Murphy KA, West JD, Kwok RS, Chiu JC. Accelerating research on spotted wing drosophila management using genomic technologies. J Pest Sci. 2016;89(3):631-41.

17. Hutter CM, Schug MD, Aquadro CF. Microsatellite variation in Drosophila melanogaster and Drosophila simulans: a reciprocal test of the ascertainment bias hypothesis. Mol Biol Evol. 1998;15(12):1620-36.

18. Amos W, Hutter CM, Schug MD, Aquadro CF. Directional evolution of size coupled with ascertainment bias for variation in drosophila microsatellites. Mol Biol Evol. 2003;20(4):660-2.
19. Kauer MO, Dieringer $D$, Schlötterer C. A microsatellite variability screen for positive selection associated with the "out of Africa" habitat expansion of Drosophila melanogaster. Genetics. 2003;165(3):1137-48.

20. Abdulazeez R, Auta J, Shehu DM, IS N, Umar AU. Determination of genetic similarities in natural populations of Drosophila Melanogaster in savanna zone of Nigeria using microsatellite markers. Mol Biol. 2016:5:177.

21. Adrion JR, Kousathanas A, Pascual M, Burrack HJ, Haddad NM, Bergland AO, Machado H, Sackton TB, Schlenke TA, Wegmann MWD, Singh ND. Drosophila suzukii: the genetic footprint of a recent, worldwide invasion. Mol Biol Evol. 2014;31(12):3148-63.

22. Bahder BW, Bahder LD, Hamby KA, Walsh DB, Zalom FG. Microsatellite variation of two Pacific coast Drosophila suzukii (Diptera: Drosophilidae) populations. Environ Entomol. 2015;44(5):1449-53.

23. Fraimout A, Loiseau A, Price DK, Xuereb A, Martin J-F, Vitalis R, Fellous S, Debat $V$, Estoup A. New set of microsatellite markers for the spottedwing Drosophila suzukii (Diptera: Drosophilidae): a promising molecular tool for inferring the invasion history of this major insect pest. Eur J Entomol. 2015;112(4):855-9.

24. Hulme PE. Trade, transport and trouble: managing invasive species pathways in an era of globalization. J Appl Ecol. 2009;46(1):10-8.

25. Cini A, Anfora G, Escudero-Colomar LA, Grassi A, Santosuosso U, Seljak G, Papini A. Tracking the invasion of the alien fruit pest Drosophila suzukii in Europe. J Pest Sci. 2014;87(4):559-66.

26. Manni M, Guglielmino CR, Scolari F, Vega-Rua A, Failloux A-B, Somboon P, Lisa A, Savini G, Bonizzoni M, Gomulski LM, Malacrida AR, Gasperi G. Genetic evidence for a worldwide chaotic dispersion pattern of the arbovirus vector, Aedes albopictus. PLoS Negl Trop Dis. 2017;11(1): e0005332.

27. Rossi-Stacconi MV, Kaur R, Mazzoni V, Ometto L, Grassi A, Gottardello A, Rota Stabelli O, Anfora G. Multiple lines of evidence for reproductive winter diapause in the invasive pest Drosophila suzukii: useful clues for control strategies. J Pest Sci. 2016;89(3):689-700.

28. Voorrips RE. MapChart: software for the graphical presentation of linkage maps and QTLs. J Hered. 2002:93(1):77-8.

29. Matschiner M, Salzburger W. TANDEM: integrating automated allele binning into genetics and genomics workflows. Bioinformatics. 2009;25(15):1982-3.

30. Peakall R, Smouse PE. GENALEX 6: genetic analysis in excel. Population genetic software for teaching and research. Mol Ecol Notes. 2006:6(1):288-95.

31. Goudet J. FSTAT (version 1.2): a computer program to calculate F-statistics. J Hered. 1995;86(6):485-6.

32. Kalinowski ST, Taper ML, Marshall TC. Revising how the computer program CERVUS accommodates genotyping error increases success in paternity assignment. Mol Ecol. 2007;16(5):1099-106.

33. Aketarawong N, Isasawin S, Sojikul P, Thanaphum S. Gene flow and genetic structure of Bactrocera carambolae (Diptera, Tephritidae) among geographical differences and sister species, $B$. dorsalis, inferred from microsatellite DNA data. Zookeys. 2015:2015(540):239-72.

34. Pickersgill B, Botany SE. Genetic diversity of cultivated tropical plants book review editor. Daniel F Austin. 2006:60(1):91-2.

35. Excoffier L, Laval G, Schneider S. Arlequin (version 3.0): an integrated software package for population genetics data analysis. Evol Bioinformatics Online. 2005;1:47-50.

36. Pritchard JK, Stephens M, Donnelly P. Inference of population structure using multilocus genotype data. Genetics. 2000;155(2):945-59.

37. Falush D, Stephens M, Pritchard JK. Inference of population structure using multilocus genotype data: linked loci and correlated allele frequencies. Genetics. 2003;164(4):1567-87.

38. Evanno G, Regnaut S, Goudet J. Detecting the number of clusters of individuals using the software STRUCTURE: a simulation study. Mol Ecol. 2005;14(8):2611-20

39. Earl DA, Von Holdt BM. STRUCTURE HARVESTER: a website and program for visualizing STRUCTURE output and implementing the Evanno method. Conserv Genet Resour. 2012;4(2):359-61.

40. Piry S, Alapetite A, Cornuet JM, Paetkau D, Baudouin L, Estoup A. GENECLASS2: a software for genetic assignment and first-generation migrant detection. J Hered. 2004;95(6):536-9.

41. Piry S, Luikart G, Cornuet JM. BOTTLENECK: a computer program for detecting recent reductions in the effective population size using allele frequency data. J Hered. 1999;90(4):502-3.

42. Chapuis MP, Estoup A. Microsatellite null alleles and estimation of population differentiation. Mol Biol Evol. 2007;24(3):621-31. 
43. Morin PA, Leduc RG, Archer Fl, Martien KK, Huebinger R, Bickham JW, Taylor BL. Significant deviations from hardy-Weinberg equilibrium caused by low levels of microsatellite genotyping errors. Mol Ecol Resour. 2009;9(2):498-504.

44. Mooney HA, Cleland EE. The evolutionary impact of invasive species. Proc Natl Acad Sci U S A. 2001;98(10):5446-51.

45. Harris RJ, Barker G. Relative risk of invasive ants (hymenoptera: Formicidae) establishing in New Zealand. New Zeal J Zool. 2007;34(3):161-78.

46. Pyšek $P$, Richardson DM. Invasive species, environmental change and management, and health. Annu Rev Environ Resour. 2010;35(1):25-55.

47. Gasperi G, Bellini R, Malacrida AR, Crisanti A, Dottori M, Aksoy S. A new threat looming over the Mediterranean Basin: emergence of viral diseases transmitted by Aedes albopictus mosquitoes. PLoS Negl Trop Dis. 2012;6(9):e1836.

48. Allendorf FW, Lundquist LL. Population biology, evolution, and control of invasive species. Conserv Biol. 2003;17(1):24-30.

49. Lee CEE. Evolutionary genetics of invasive species. Trends Ecol Evol. 2002; 17(8):386-91.

50. Ometto L, Cestaro A, Ramasamy S, Grassi A, Revadi S, Siozios S, Moretto M, Fontana P, Varotto C, Pisani D, Dekker T, Wrobel N, Viola R, Pertot I, Cavalieri D, Blazter M, Anfora G, Rota SO. Linking genomics and ecology to investigate the complex evolution of an invasive drosophila pest. Genome Biol Evol. 2013;5(4):745-57.

51. Crava CM, Ramasamy S, Ometto L, Anfora G, Rota-Stabelli O. Evolutionary insights into taste perception of the invasive Pest Drosophila suzukii. G3 (Bethesda). 2016;6:4185-96.

52. Ramasamy S, Ometto L, Crava MC, Revadi S, Kaur R, Horner DS, Pisani D, Dekker T, Anfora G, Rota SO. The evolution of olfactory gene families in drosophila and the genomic basis of chemical-ecological adaptation in Drosophila suzukii. Genome Biol Evol. 2016;8(8):2297-311.

53. Kučerová L, Kubrak Ol, Bengtsson JM, Strnad H, Nylin S, Theopold U, Nassel DR. Slowed aging during reproductive dormancy is reflected in genomewide transcriptome changes in Drosophila melanogaster. BMC Genomics. 2016;17(1):50.

54. Giampetruzzi A, Morelli M, Saponari M, Loconsole G, Chiumenti M, Boscia D, Savino VN, Martelli GP, Saldarelli P. Transcriptome profiling of two olive cultivars in response to infection by the CoDiRO strain of Xylella fastidiosa subsp. pauca. BMC Genomics. 2016;17(1):475.

55. Champion $\mathrm{CJ}, \mathrm{Xu}$ J. The impact of metagenomic interplay on the mosquito redox homeostasis. Free Radic Biol Med. 2017;105:79-85.

56. Sardi S, Somasekar S, Naccache SN, Bandeira AC, Tauro LB, Campos GS, Chiu CY Co-infections from Zika and Chikungunya virus in Bahia, Brazil identified by metagenomic next-generation sequencing. J Clin Microbiol. 2016;54(9):2348-53.

57. Miller B, Anfora G, Buffington M, Daane KM, Dalton DT, Hoelmer KM, Rossi Stacconi MV, Grassi A, loriatti C, Loni A, Miller JC, Quantar M, Wang W, Wiman NG, Walton VM. Seasonal occurrence of resident parasitoids associated with Drosophila suzukii in two small fruit production regions of Italy and the USA. Biol Con. 2015;68(2):255-63.

58. Mazzetto F, Marchetti E, Amiresmaeili N, Sacco D, Francati S, Jucker C, Dindo L, Lupi D, Tavella L. Drosophila parasitoids in northern Italy and their potential to attack the exotic pest Drosophila suzukii. J Pest Sci. 2016;89(3):837-50.

59. Lengyel GD, Orosz S, Kiss B, Lupták R, Kárpáti Z. New records and present status of the invasive spotted wing drosophila, Drosophila suzukii (Matsumura, 1931) (Diptera) in Hungary. Acta Zool Acad Sci Hungaricae. 2015;61(1):73-80

60. Benedict MQ, Levine RS, Hawley WA, Lounibos LP. Spread of the tiger: global risk of invasion by the mosquito Aedes albopictus. Vector Borne Zoonotic Dis. 2007;7(1):76-85.

61. Goergen G, Vayssières J-F, Gnanvossou D, Tindo M. Bactrocera invadens (Diptera: Tephritidae), a new invasive fruit fly Pest for the Afrotropical region: host plant range and distribution in west and Central Africa. Environ Entomol. 2011;40(4):844-54

62. Pimentel D, Zuniga R, Morrison D. Update on the environmental and economic costs associated with alien-invasive species in the United States Ecol Econ. 2005;52(3):273-88.

\section{Submit your next manuscript to BioMed Central and we will help you at every step:}

- We accept pre-submission inquiries

- Our selector tool helps you to find the most relevant journal

- We provide round the clock customer support

- Convenient online submission

- Thorough peer review

- Inclusion in PubMed and all major indexing services

- Maximum visibility for your research

Submit your manuscript at www.biomedcentral.com/submit

) Biomed Central 